\title{
Acid-mediated reactions under microfluidic conditions: A new strategy for practical synthesis of biofunctional natural products
}

\author{
Katsunori Tanaka and Koichi Fukase
}

\author{
Review \\ Address: \\ Department of Chemistry, Graduate School of Science, Osaka \\ University, 1-1 Machikaneyama, Toyonaka, Osaka, 560-0043, Japan \\ Email: \\ Koichi Fukase* - koichi@chem.sci.osaka-u.ac.jp \\ * Corresponding author \\ Keywords: \\ acid-mediated reaction; microreactor; natural products synthesis; \\ oligosaccharide; pristane
}

Beilstein Journal of Organic Chemistry 2009, 5, No. 40. doi:10.3762/bjoc. 5.40

Received: 01 April 2009

Accepted: 20 July 2009

Published: 20 August 2009

Guest Editor: A. Kirschning

() 2009 Tanaka and Fukase; licensee Beilstein-Institut. License and terms: see end of document.

\begin{abstract}
Microfluidic conditions were applied to acid-mediated reactions, namely, glycosylation, reductive opening of the benzylidene acetal groups, and dehydration, which are the keys to the practical synthesis of $\mathrm{N}$-glycans and the immunostimulating natural product, pristane. A distinctly different reactivity from that in conventional batch stirring was found; the vigorous micromixing of the reactants with the concentrated acids is critical especially for the "fast" reactions to be successful. Such a common feature might be due to the integration of all favorable aspects of microfluidic conditions, i.e., efficient mixing, precise temperature control, and the easy handling of the reactive intermediate by controlling the residence time. The microfluidic reactions cited in this review indicate the need to reinvestigate the traditional or imaginary reactions which have so far been performed and evaluated only in batch apparatus, and therefore they could be recognized as a new strategy in synthesizing natural products of prominent biological activity in a "practical" and a "industrial" manner.
\end{abstract}

\section{Introduction}

A continuous flow microreactor, an innovative technology, has been used to realize efficient mixing and fast heat transfer in organic syntheses [1-26]. The flow system allows the reaction to be quenched immediately after the formation of the unstable products. Furthermore, once the reaction conditions are optimized for a small-scale operation, the same conditions are directly applicable to large-scale synthesis under the flow process. We have been applying these advantageous features of the micro- fluidic systems to the "key" but "problematic" acid-mediated reactions under the conventional batch apparatus, in practically preparing bioactive natural products [27-33]. Our successful examples are cation-mediated reactions, such as $\alpha$-sialylation [28,32], $\beta$-mannosylation [31], and reductive opening of the benzylidene acetal groups in sugars [30], for which improved procedure under the microfluidic conditions enabled the preparation of key synthetic intermediates for oligosaccharides on a 
multi-gram scale, eventually leading to a total synthesis of the asparagine-linked oligosaccharide ( $N$-glycan) [32]. A significant improvement has also been achieved for dehydration, which resulted in the industrial scale-synthesis of the immunostimulating natural terpenoid, pristane, of about $500-1000 \mathrm{~kg}$ in a year [29]. In this account, we review these acid-mediated reactions and discuss the new aspects of using microfluidic systems for controlling the hitherto difficult reactions in conventional organic synthesis; microfluidic reactions can offer a direct and practical route to the desired compounds without the usual scale-up problems associated with mixing efficiency and the temperature control. They can therefore be regarded as one of the new strategies for the practical synthesis, or in favorable cases, the industrial synthesis of the bioactive natural products.

\section{Review}

\section{Application of microfluidic systems to the synthesis of asparagine-linked oligosacchar- ides}

Among the various types of oligosaccharide structures, asparagine-linked oligosaccharides ( $N$-glycans) are prominent in terms of diversity and complexity [34]. It is becoming clear that they are involved in a variety of important physiological events, such as cell-cell recognition, adhesion, signal transduction, quality control, and circulatory residence of proteins [35-38]. However, isolating large quantities of structurally pure $N$-glycans from natural sources is difficult. Thus, chemical synthesis provides an attractive opportunity to evaluate their biological functions. Although a number of new chemical and/or combined methods employing biological technology have actively been investigated $[39,40]$, an efficient approach to these complex oligosaccharides has yet to be established in terms of (i) selectivity in the glycosyl bond formations, i.e., $\beta$-mannosylation and $\alpha$-sialylation, and (ii) a non-tedious purification process during each step of glycosylation and deprotection. Our interests in elucidating unknown biological functions of mammalian $\mathrm{N}$-glycans of the diverse structures, have motivated us to establish a practical and library-directed synthesis of the complextype $N$-glycans on solid-support [32]; the initial target of our strategy is a sialic acid-containing $N$-glycan with asymmetric branching chains (Figure 1), which is difficult to obtain from natural sources. To prepare the target $N$-glycan as well as other diverse structures of this family in an efficient manner, we designed fragments a-d with $N$-phenyltrifluoroacetimidate as the leaving group, which can be efficiently glycosylated on solid-support to construct the $\mathrm{N}$-glycan structures. Herein, two challenging glycosyl bond formations, i.e., $\beta$-mannosylation and $\alpha$-sialylation, were carried out in advance in solution, by the aid of the microfluidic systems (Figure 1) [28,31,32]. The problem of the key protecting group manipulation, i.e., the reductive opening of benzylidene acetal group, for the large-scale preparation of the fragment $\mathbf{b}[30]$ could also be circumvented under
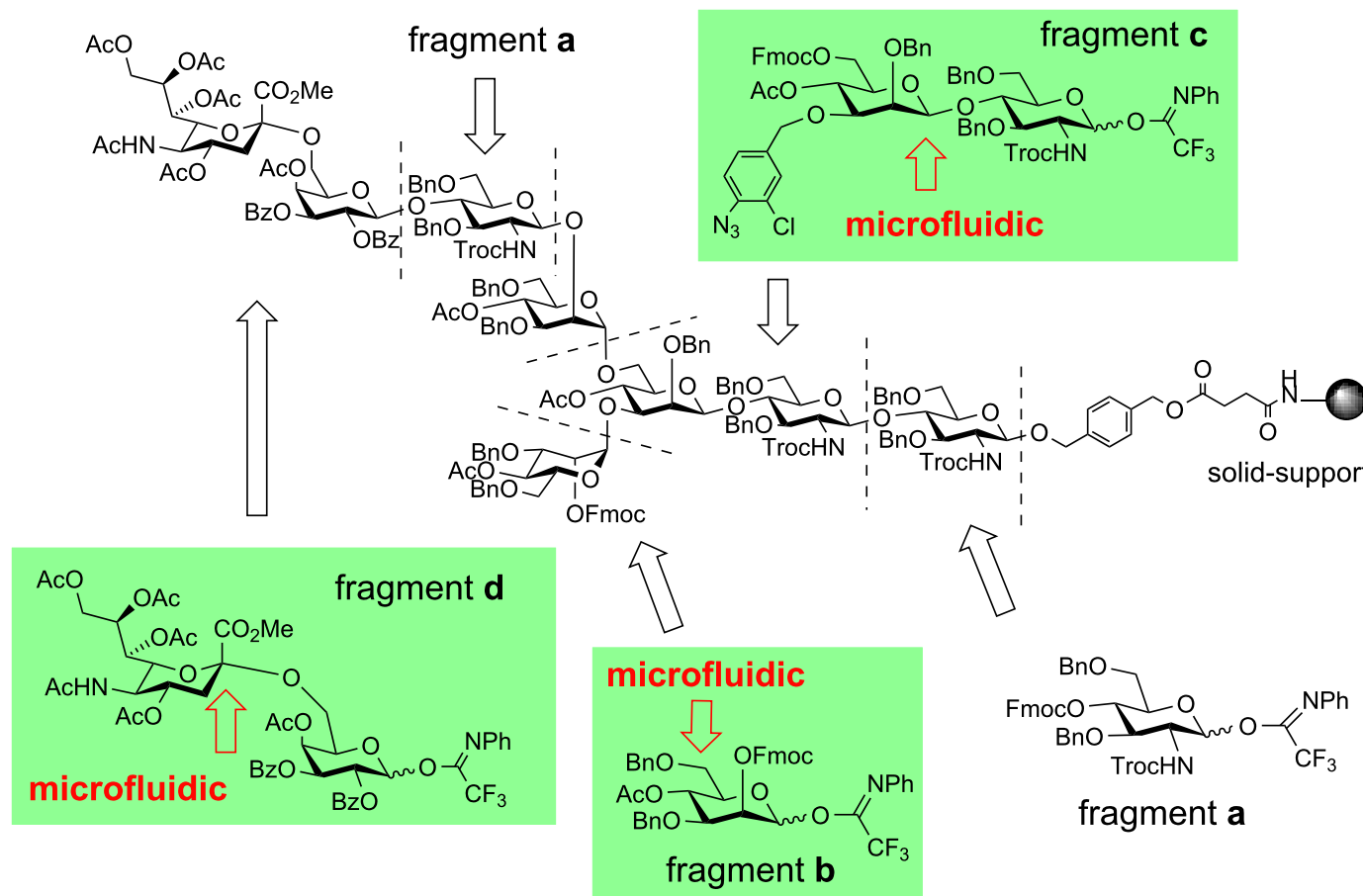

fragment a

Figure 1: Synthetic strategy for asparagine-linked oligosaccharide on solid support and application of microfluidic systems to fragment synthesis. 
the microfluidic conditions, as will be discussed in the following sections.

\section{Microfluidic $\alpha$-sialylation}

We have previously developed an efficient $\alpha$-sialylation by utilizing the highly reactive sialyl donors having C-5 cyclic imides (Table 1), especially $N$-phthalimide 1a, by virtue of the "fixeddipole moment effects" ( $\alpha$-only, 92\% on $50 \mathrm{mg}$ scale) [41]. The scale-up in a batch process, however, significantly decreased the yield and selectivity. Thus, a $100 \mathrm{mg}$ scale reaction of $\mathbf{1 a}$ gave only $60 \%$ of $\alpha$-sialoside accompanied by a significant amount of a glycal by-product. The decrease in sialylation efficiency might be due to the high reactivity of the donor 1a. For such a case, precise reaction control is very difficult under the conventional batch process conditions, especially when the reaction is scaled-up. Thus, the disorder of the reaction factors in the scaled-up batch reaction, i.e., (i) precise temperature control, (ii) mixing efficiency between acceptor, donor, and Lewis acid, and (iii) reaction time, might lead to the glycal production. In order to circumvent these problems, we used a continuous flow microreactor. An application of the microfluidic system to the glycosylation reaction was first reported by Seeberger and co-workers on $\alpha$-mannosylation [18]. We also have established an efficient microfluidic glycosylation in combination with the affinity separation method [27].

For the present microfluidic sialylation, a propionitrile solution of sialyl donor 1a and acceptor $\mathbf{2}$ with various concentrations was mixed with TMSOTf solution in dichloromethane at $-78^{\circ} \mathrm{C}$ using an IMM micromixer [42] with a channel width of $40 \mu \mathrm{m}$ at a flow rate of $1.0 \mathrm{~mL} / \mathrm{min}$ (Table 1 ). After the reaction mixture was allowed to flow at $-78{ }^{\circ} \mathrm{C}$ for an additional 47 seconds through a reactor tube $(\varnothing=1.0 \mathrm{~mm}, l=1.0 \mathrm{~m})$, the mixture was quenched by another flow of excess triethylamine dissolved in dichloromethane by using a T-shaped mixer at $-78{ }^{\circ} \mathrm{C}$. When the concentrations of the donor $\mathbf{1 a}$, acceptor $\mathbf{2}$, and TMSOTf were adjusted to $0.15 \mathrm{M}, 0.1 \mathrm{M}$, and $0.08 \mathrm{M}$, respectively, disaccharide 3a was obtained in only $14 \%$ yield and a large amount of the acceptor 2 was recovered (entry 1). However, we were pleased to find that the yield of $\mathbf{3 a}$ dramatically increased (88\%) when the concentration of the Lewis acid was increased to $0.15 \mathrm{M}$ (entry 2). Finally, the desired $\alpha$-sialoside 3a was obtained in quantitative yield by increasing the concentration of the donor 1a to $0.2 \mathrm{M}$ (entry 3 ). Thus, the microfluidic reaction successfully controlled the high reactivity of the sialyl donor 1a for $\alpha$-sialylation. Obviously, vigorous and rapid mixing of the substrates with the high concentrations of the acid is responsible for the success of the microfluidic sialylation; the trend is completely different from that of the corresponding batch reaction, since the decomposition of the donor has long been regarded as a severe problem under such drastic conditions [41]. The use of excess amounts of donor 1a and/or TMSOTf in batch reaction did not improve the sialylation yield, but rather resulted in a large amount of glycal production. Apparently, the efficient micromixing between substrates and the high concentration of the acid should accelerate the reaction, while the rapid heat transfer prevented the undesired hydrolysis and glycal formation. The "flow system"

Table 1: Optimization of $\alpha(2-6)$-sialylation using IMM micromixer.

$1 \mathbf{a}: \mathrm{R}=\mathrm{NPht}$
$\mathbf{1 b}: \mathrm{R}=\mathrm{N}_{3}$

aBatch results: $92 \%$, $\alpha$-only on $50 \mathrm{mg}$ scale; $60 \%, \alpha: \beta=97: 3$ on $100 \mathrm{mg}$ scale. ${ }^{b}$ Batch results: $90 \%, \alpha: \beta=9: 1$ on $100 \mathrm{mg}$ scale. ${ }^{c}$ Mainly, glycal derived from $1 \mathrm{a}$ and acceptor 2 were recovered by TLC analysis. ${ }^{d}$ Based on ${ }^{1} \mathrm{H}$ NMR analysis. 
also enabled the residence time to be controlled before the decomposition of sialoside 3a under the strongly acidic conditions. This new aspect under microfluidic conditions was found to be general to the acid-mediated reactions, and similar results can be seen in the following sections.

Unfortunately, the selective deprotection of the $N$-phthalyl group in the presence of the $\mathrm{C}-1$ methoxycarbonyl in 3a was troublesome on the $1-2 \mathrm{~g}$ reaction scale. As an alternative to the $\mathrm{N}$-phthalyl function, we also employed the C-5 azide group in sialyl donor $\mathbf{1 b}$ because this azide group should direct similar "fixed-dipole moment effects", but should be easier to convert to naturally occurring $N$-substituents of neuraminic acids, i.e., $\mathrm{N}$-acetyl or $\mathrm{N}$-glycolyl groups (see structure in Figure 1) [32]. As anticipated, sialylation between $\mathbf{1 b}$ and galactosyl acceptor $\mathbf{2}$ in the presence of TMSOTf as an activator and $4 \AA$ molecular sieves in propionitrile provided $\mathbf{3 b}$ in $90 \%$ yield with good $\alpha$-selectivity ( $\alpha: \beta=9: 1$ on $100 \mathrm{mg}$ scale). Furthermore, applying the continuous microfluidic sialylation, which was established for the $N$-phthalyl derivative 1a (Table 1, entry 3), improved both the yield and $\alpha$-selectivity (entry 4 ): $\mathbf{3 b}$ was obtained quantitatively with near perfect $\alpha$-selectivity ( $\alpha: \beta=$ $20: 1)$. The $\alpha$ and $\beta$ stereoisomers were easily separated by chromatography on silica-gel, and the pure $\alpha$-isomer was readily converted to the desired imidate fragment $\mathbf{d}$ (Figure 1) using the general procedure. Hence, we successfully prepared fragments $\mathbf{d}$ on the $5-10 \mathrm{~g}$ scale [32].

\section{Microfluidic $\beta$-mannosylation}

Stereoselective formation of the $\beta$-mannoside linkage, a key glycosylation in the synthesis of the $\beta \operatorname{Man}(1 \rightarrow 4)$ GlcNTroc fragment $\mathbf{c}$ of $N$-linked glycans, is another challenging topic in oligosaccharide synthesis. Various methods, such as intramolecular aglycon delivery (IAD) or glycosylation with
4,6-O-benzylideneacetal-protected $\alpha$-mannosyltriflates, have recently been reported and successfully applied to $\beta$-mannoside synthesis $[31,39,40,43-45]$. We also have achieved excellent $\beta$-selectivity in the reaction of 4,6-O-benzylidenemannopyranosyl- $N$-phenyltrifluoroacetimidate (4) with $N$-Trocglucosamine acceptor $5(\mathrm{R}=\mathrm{Bn}, 93 \%$ yield, $\beta: \alpha=95: 5$ on 20 $\mathrm{mg}$ scale) using the bulky and dual Lewis acid/cation trap reagent, $\operatorname{TMSB}\left(\mathrm{C}_{6} \mathrm{~F}_{5}\right)_{4}$ (Table 2, entry 1) $[46,47]$.

Nevertheless, it is difficult to apply our $\beta$-mannosylation protocol to a few gram-scale synthesis of the $\beta$ Man $(1 \rightarrow 4)$ GlcNTroc fragment $\mathbf{c}$ because the scaled-up glycosylation requires a large quantity of the bulky $\operatorname{TMSB}\left(\mathrm{C}_{6} \mathrm{~F}_{5}\right)_{4}$ activator, which has limited commercial availability [46,47]. Therefore, from a practical viewpoint for preparing the fragment $\mathbf{c}$ as a starting material, we refocused on applying the more common TMSOTf as a glycosyl activator because our earlier experiments indicated that TMSOTf shows a good yield and $\beta$-selectivity on a $20 \mathrm{mg}$ scale ( $90 \%$ yield, $\beta: \alpha=93: 7)$ (entry 2) [46]. However, the efficiency of glycosylation catalyzed by TMSOTf is extremely sensitive to the reaction scale as well as the addition speed of the Lewis acid (entries 2-5). When TMSOTf was added dropwise to a solution of mannosyl donor 4 and acceptor 5 at $-78^{\circ} \mathrm{C}$, the yield of $\beta$-mannoside 6 gradually decreased as the reaction scale increased (entries $2-4)$. On a $50 \mathrm{mg}$ scale, $63 \%$ of $\beta$-disaccharide 6 was isolated, whereas only $27 \%$ of $\beta$-isomer 6 was obtained on a $500 \mathrm{mg}$ scale (entries 3 and 4). For an unknown reason, slow addition of a Lewis acid in the larger scale reactions inhibited the glycosylation process at an earlier stage [31]. Moreover, even the subsequent addition of the TMSOTf catalyst did not activate the glycosylation between the remaining starting materials. These results cannot be clearly explained based on presently available data. On the other hand, when the acid was added to the initial solution of $\mathbf{4}$

Table 2: $\beta$-Mannosylation under batch conditions

\begin{tabular}{|c|c|c|c|c|c|c|}
\hline \multirow[b]{2}{*}{ Entry $^{a}$} & \multirow[b]{2}{*}{ Lewis acids } & $\underbrace{\text { TrocHN }}_{5}$ & $\begin{array}{c}\text { Lewis acids }(15-20 \mathrm{~m} \\
\mathrm{CH}_{2} \mathrm{Cl}_{2}, \mathrm{MS} 4 \mathrm{~A},-78^{\circ} \\
12 \mathrm{~h}\end{array}$ & \multicolumn{2}{|c|}{$\mathrm{R}=\mathrm{Bn}$ or $\mathrm{AzClBn}$} & OAllyl \\
\hline & & Addition of LA & scale $(\mathrm{mg})$ & Yield $(\%)^{b}$ & $\beta: \alpha^{c}$ & \\
\hline 1 & $\operatorname{TMSB}\left(\mathrm{C}_{6} \mathrm{~F}_{5}\right)_{4}$ & dropwise & 20 & 88 & $95: 5$ & \\
\hline 2 & TMSOTf & dropwise & 20 & 84 & $93: 7$ & \\
\hline 3 & TMSOTf & dropwise & 50 & $63^{d}$ & NA & \\
\hline 4 & TMSOTf & dropwise & 500 & $27^{d}$ & NA & \\
\hline 5 & TMSOTf & in one portion & 900 & $61^{d}$ & $4.9: 1$ & \\
\hline
\end{tabular}

${ }^{a}$ Reaction is performed using 1.5 equiv of donor $\mathbf{4}$ relative to acceptor $\mathbf{5}$. ${ }^{b}$ Isolated yields for $\beta$-isomer. ${ }^{C}$ Based on ${ }^{1} \mathrm{H}$ NMR analysis. ${ }^{d}$ Additionally, acceptor $\mathbf{5}$, its silylated derivative, and decomposed products of $\mathbf{4}$ were obtained by TLC analysis. 


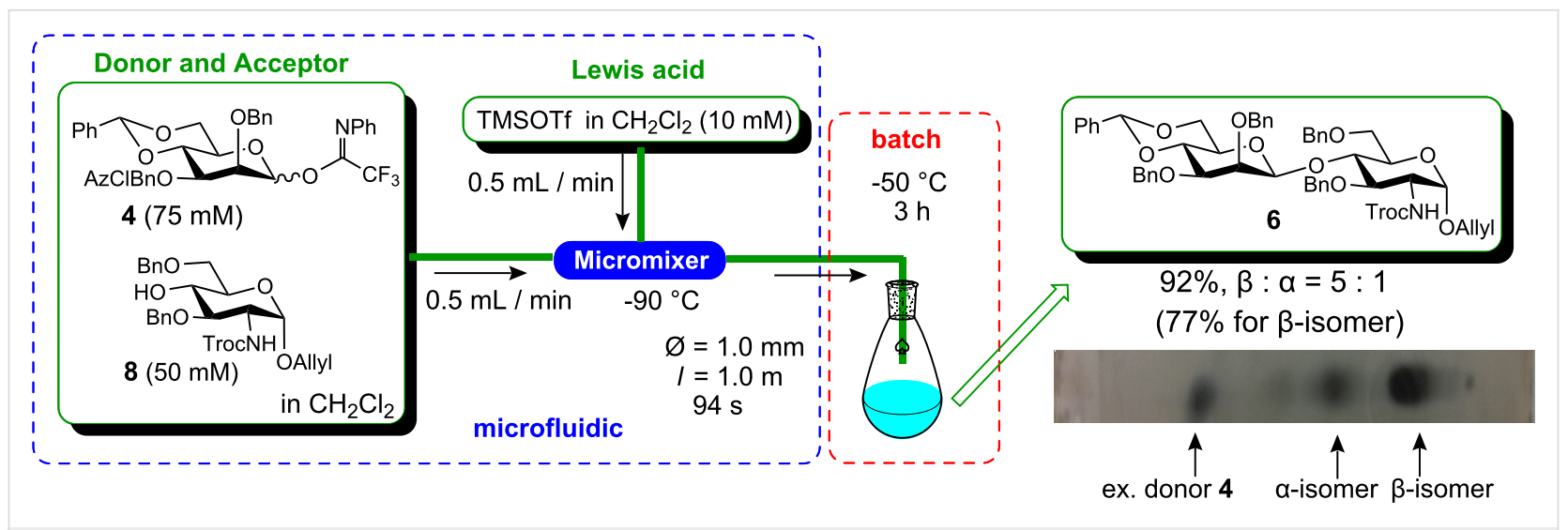

Figure 2: $\beta$-Mannosylation using an integrated microfluidic/batch system. Yield and $\beta / \alpha-$ ratio are analyzed by ${ }^{1} \mathrm{H}$ NMR and HPLC.

and $\mathbf{5}$ in one portion, mannosylation proceeded smoothly (entry 5). However, the $\beta$-selectivity decreased to $4.9: 1$, presumably due to the exothermic nature of the reaction, i.e., heat is generated while rapidly mixing, which leads to an overall decrease in the isolated yield of $\beta$-disaccharide 6 ( $61 \%$ on $900 \mathrm{mg}$ scale) Therefore, we decided to examine the microfluidic conditions based on the observations shown in Table 2, which indicate that the success of the current glycosylation depends on the fast addition and the efficient mixing with the Lewis acid to produce the active intermediates at the low temperature, which subsequently and slowly reacted with the acceptor $\mathbf{5}$ in batch apparatus.

We initially constructed the microfluidic system shown in Figure 2, based on our previous experiences with microfluidic $\alpha$-sialylation [28,32]. In addition to the aspects mentioned above, an attractive feature of the microfluidic reaction is that the reaction can be readily optimized under the flow process [18]; the optimal conditions, i.e., concentrations of the substrates, mixing speed, temperature, and residence time, are rapidly determined using a small quantity of materials. For this optimization, we have used the Comet X-01 micromixer [48] with a channel width of ca. $500 \mu \mathrm{m}$, where the micromixing with IMM mixer $(40 \mu \mathrm{m})$ caused the significant solution blockage problems due to the low solubility of both the donor 4 and the acceptor $\mathbf{5}$ in dichloromethane at very low temperature of -78 to $-90{ }^{\circ} \mathrm{C}$. Rapid screening of more than 30 conditions in a combinatorial fashion led to a new reaction system where the microfluidic system is integrated with a conventional batch apparatus (Figure 2) [31]. Namely, the reaction solution resulting from efficient micromixing between the reactants at a low temperature, was subsequently inserted into the batch system, and then was conventionally stirred in a flask for a few hours to complete the reaction. Although it is theoretically possible to maintain an indefinite residence time by increasing the reactor tube length, under certain conditions, i.e., when the reaction has to proceed for more than an hour, employing an extremely long tube is impractical. The optimal conditions in the integrated microfluidic/batch apparatus as depicted in Figure 2, i.e., micromixing at $-90{ }^{\circ} \mathrm{C}$ and a batch reaction at $-50{ }^{\circ} \mathrm{C}$ for $3 \mathrm{~h}$, provided $\alpha / \beta$-mannoside $6(\mathrm{R}=\mathrm{Bn})$ in $92 \%$ yield and with a moderate $\beta$-selectivity $(\beta: \alpha=5.0: 1)$. Under the established conditions, mannosylation proceeds gradually in the flask, by TLC analysis. It should be noted that although the $\beta$-selectivity was somewhat lower than that observed in the small-scale batch reaction (Table 2, entry 2), the isolated $\beta$-mannoside 6 could be obtained with similar efficiency (77\% for microfluidic reaction versus $84 \%$ for $20 \mathrm{mg}$ scale batch reaction) [31]. Moreover, under the established conditions, the compound 6 was reproducibly obtained even in the scaled-up synthesis by simply preparing stock solutions of substrates and reagents, and then continuously pumping them into the integrated microfluidic/batch system. Thus, the reproducibility and scaled-up preparation of $\mathbf{6}$, and hence the fragment $\mathbf{c}$, is noteworthy from the viewpoint of preparing an important synthetic intermediate for complex $\mathrm{N}$-glycans.

\section{Microfluidic reductive opening of sugar 4,6-O- benzylidene acetals}

The microfluidic conditions can also be applied to an efficient procedure for the reductive opening of 4,6- $O$-benzylidene acetals [30], a key functional group manipulation toward fragment $\mathbf{b}$ for our $N$-glycan synthesis. Reductive opening of sugar 4,6-O-benzylidene acetals by the combination of acid/hydride reagents is one of the most useful transformations in the field of carbohydrate chemistry [49], not only for our current $N$-glycan case, since the benzyl-protected derivatives at either the C4- or C6-hydroxyl can be selectively prepared by the choice of reagent and/or solvent systems [50,51].

The typical procedure of the reductive opening of the acetals involves the very slow addition of the acid to a mixture of the 
substrate and excess hydride reagent at $0{ }^{\circ} \mathrm{C}$, followed by continuous stirring at room temperature for another few hours to ensure the completion of the reaction. Since the reaction is exothermic, it is important to control the addition speed of the acid in order to prevent concomitant acid-catalyzed hydrolysis of the benzylidene groups. However, the yields are not always reproducible, especially when the reaction is performed in a large scale, giving rise to the hydrolyzed by-products, 4,6-Odiols. The precise temperature control and the mixing efficiency between the substrate, acid, and hydride source are critical for this transformation. In order to facilitate the synthetic procedure, therefore, we used a continuous flow microreactor.

Optimal conditions for reductive opening of 4,6-O-benzylidene acetals by a microfluidic system, similar to the $\alpha$-sialylation and the $\beta$-mannosylation protocols, were examined using the glucose 4,6-O-benzylidene acetal 7 (Table 3). Benzylidene acetal $7(0.1 \mathrm{M})$ and $\mathrm{Et}_{3} \mathrm{SiH}(1.0 \mathrm{M})$ dissolved in $\mathrm{CH}_{2} \mathrm{Cl}_{2}$ were mixed with various concentrations of $\mathrm{BF}_{3} \cdot \mathrm{OEt}_{2}$ in $\mathrm{CH}_{2} \mathrm{Cl}_{2}$ (0.1-1.0 M) at $0{ }^{\circ} \mathrm{C}$ using a Comet X-01 micromixer [48] at the flow rate of $0.5 \mathrm{~mL} / \mathrm{min}$. After the reaction mixture was allowed to flow at room temperature for approximately 90 seconds

Table 3: Reductive opening of benzylidene acetals under microfluidic conditions.

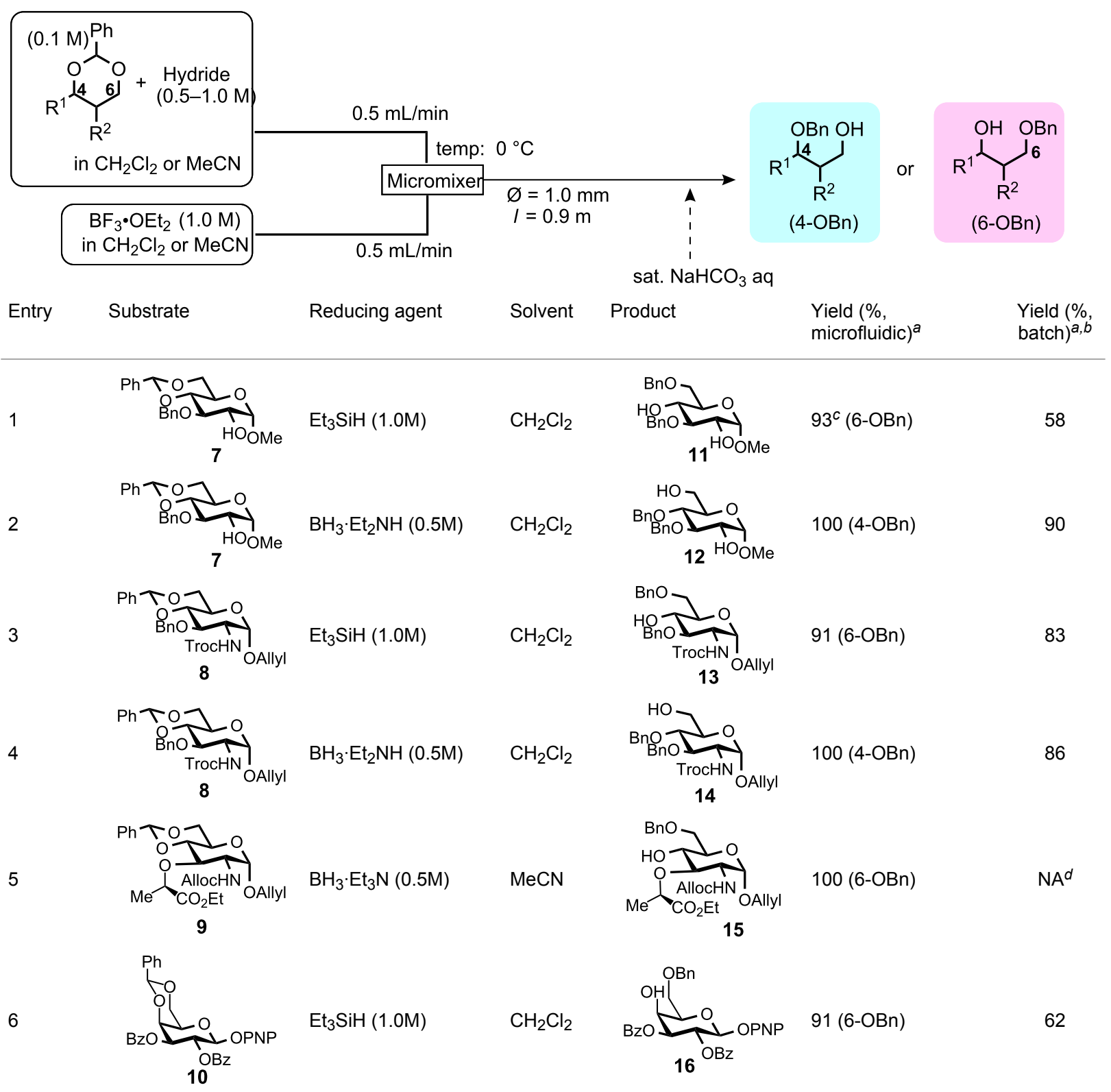

${ }^{a}$ Isolated yields. ${ }^{b}$ Reaction was performed at $100-500 \mathrm{mg}$ scale. ${ }^{c} 4-O-B e n z y l$ derivative was obtained in $5 \%$ yield. ${ }^{d} 60-70 \%$ Yields for the case of corresponding $N$-Troc derivative. ${ }^{e} P N P$ : $p$-nitrophenol. 
through a reactor tube $(\varnothing=1.0 \mathrm{~mm}, l=0.9 \mathrm{~m})$, the mixture was quenched by saturated $\mathrm{NaHCO}_{3}$ solution at $0{ }^{\circ} \mathrm{C}$.

When $0.1 \mathrm{M}$ solution of $\mathrm{BF}_{3} \cdot \mathrm{OEt}_{2}$ in $\mathrm{CH}_{2} \mathrm{Cl}_{2}$ was used, only a hydrolyzed compound was obtained in about $50 \%$ yield accompanied with recovery of the starting material 7 . However, the yield of 6-O-benzyl derivative $\mathbf{1 1}$ dramatically increased when the concentration of $\mathrm{BF}_{3} \cdot \mathrm{OEt}_{2}$ was increased up to $1.0 \mathrm{M}$; the desired 11 was obtained in $93 \%$ yield together with $5 \%$ of the 4-O-benzyl derivative 12, and no hydrolyzed by-product was detected (Table 3, entry 1 ). Surprisingly, the reaction with a more concentrated $\mathrm{BF}_{3} \cdot \mathrm{OEt}_{2}$ solution $\left(\mathrm{BF}_{3} \cdot \mathrm{OEt}_{2}: \mathrm{CH}_{2} \mathrm{Cl}_{2}=1\right.$ : 1) also provided $\mathbf{1 1}$ in quantitative yield. The reaction is very rapid and $\mathbf{1 1}$ was obtained within a minute after mixing with the acid in the micromixer device. These results are in marked contrast to those of the batch reaction, which requires dilution of the Lewis acid and longer reaction time in order to keep the hydrolysis to a minimum. Very similar to the microfluidic $\alpha$-sialylation described above, the rapid and vigorous mixing with the highly concentrated acid was critical for the acid-mediated microfluidic reaction to be successful.

Gratifyingly, by applying the established conditions above, the glucose, glucosamine, and galactose 4,6- $O$-benzylidene acetals 7-10 were selectively transformed into the corresponding 4- or 6-O-benzyl derivatives $\mathbf{1 2 - 1 6}$ in nearly quantitative yields (entries 2-6). Thus, the treatment of 7 with $\mathrm{BH}_{3} \cdot \mathrm{Et}_{2} \mathrm{NH}$ selectively provided 4-O-benzyl derivative $\mathbf{1 2}$ in quantitative yield (entry 2). The benzylidene group of glucosamine derivative $\mathbf{8}$ was also selectively cleaved under the microfluidic conditions by utilizing either $\mathrm{Et}_{3} \mathrm{SiH}$ or $\mathrm{BH}_{3} \cdot \mathrm{Et}_{2} \mathrm{NH}$ as a hydride source to provide the 6- and 4-O-benzyl derivatives 13 and 14 in excellent yields, respectively (entries 3 and 4). The $\mathrm{BH}_{3} \cdot \mathrm{Et}_{3} \mathrm{~N}$ in $\mathrm{MeCN}$ system was also applicable to the microflow reduction of muramic acid derivative 9 , which contains a lactic acid ester at the $\mathrm{C} 3$-hydroxyl, affording 6-O-benzyl derivative $\mathbf{1 5}$ as a single isomer (entry 5). Finally, the selective reduction of galactose derivative $\mathbf{1 0}$ gave the 6-O-benzyl derivative $\mathbf{1 6}$ in $91 \%$ yield (entry 6 ). It is worthwhile mentioning that the established microfluidic reaction reproducibly provided the
O-benzylated compounds $\mathbf{1 1 - 1 6}$ in greater than $90 \%$ yields in all cases, out of the three experiments performed in each entry of Table 3. Furthermore, no special dehydration procedures, such as pre-drying of the reaction apparatus and the solvents by molecular seives, are necessary, making the present microflow reaction a practical procedure for large-scale synthesis [30]. Based on the established microfluidic protocol, fragment $\mathbf{b}$ for the $N$-glycan synthesis, was continuously and reproducibly obtained even on a 10-gram scale [32].

The successful application of the microfluidic systems to the three hitherto "difficult" acid-mediated reactions under the conventional batch conditions, namely, $\alpha$-sialylation, $\beta$-mannosylation, as well as reductive opening of sugar 4,6-Obenzylidene acetals, significantly facilitated the large scale preparation of the $N$-glycan fragments $\mathbf{b}-\mathbf{d}$. A stock of these key synthetic intermediates eventually led to the first solidsupported synthesis of the sialic acid-containing complex-type $N$-glycan (Figure 1) [32].

\section{Microfluidic dehydration: a process synthesis of immunoactivating natural product, pristane}

2,6,10,14-Tetramethylpentadecane (pristane) is a saturated isoprenoid isolated from the basking shark, Cetorhinus maximus [52-56]. This hydrocarbon oil is known to induce tumorigenesis in mice and arthritis and lupus nephritis in rats, and has been widely used as an adjuvant for monoclonal antibody production in mouse ascites [57-59]. However, in 2002, the basking shark was listed on Article II of the Washington Convention (Convention on International Trade in Endangered Species of Wild Fauna and Flora), and since then, the availability of pristane from a natural source became very limited. Therefore, an efficient chemical synthesis of pristane has been long desired.

When considering the synthesis of this simple hydrocarbon in a non-stereoselective manner, one can immediately come up with a commonplace route, i.e., oxidation of farnesol 17, alkylation, dehydration, and hydrogenation, as shown in Scheme 1. The

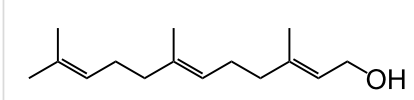

farnesol 17

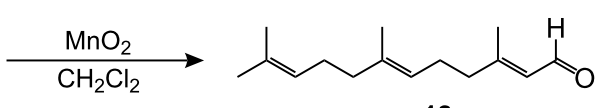

18
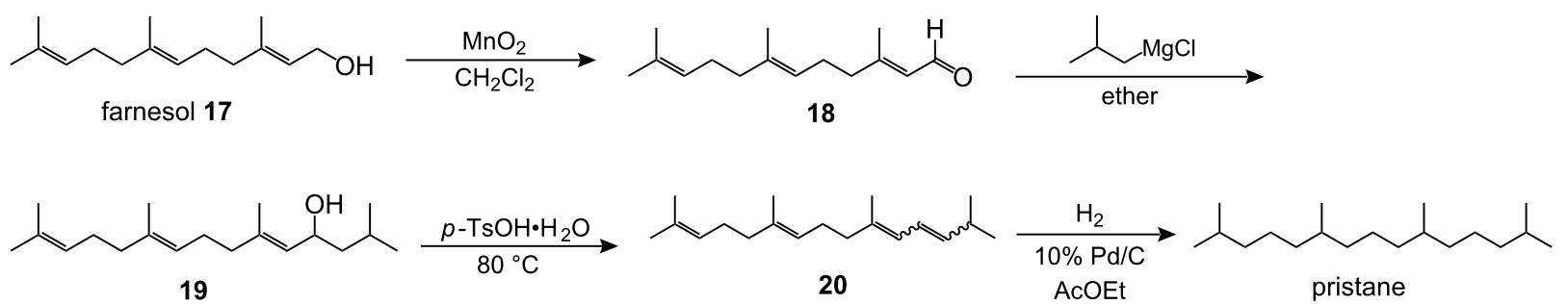

Scheme 1: Synthesis of pristane. 
synthesis is quite simple when $50 \mathrm{mg}$ of the sample is prepared, but it suddenly becomes difficult when $200 \mathrm{~kg}$ of this hydrocarbon is required in a year with more than $98 \%$ purity. Namely, the preparation of $5 \mathrm{~kg}$ of pristane in about a week is necessary in order to supply enough material in the market.

The challenging step in Scheme 1 is the acid-catalyzed dehydration of allylic alcohol 19. When the reaction was performed in $100 \mathrm{mg}$ scale using a catalytic amount of $p$-TsOH in benzene at $80^{\circ} \mathrm{C}$, the corresponding diene $\mathbf{2 0}$ was obtained in $55 \%$ yield as its $(E)$ - and $(Z)$-stereoisomers, which was transformed to pristane by hydrogenation. However, when the scale was raised to $100 \mathrm{~g}$, various cation-mediated by-products, such as the cyclized products or the alkyl group-migrated compounds were produced. As expected, these hydrocarbons were very difficult to separate from the desired diene $\mathbf{2 0}$, even by repeated distillation or by silica gel chromatography, although the latter is not realistic for kilogram-scale purification.

Inspired by the successful application of the microfluidic systems to the acid-mediated reactions during the $N$-glycan synthesis described above, we examined the microfluidic dehydration under the following conditions (Figure 3) [29]: Allylic alcohol 19 (1.0 M in THF) was mixed with a solution of $p$-TsOH (various concentrations of $0.2-1.0 \mathrm{M}$ in THF : toluene $=1: 1)$ at $90{ }^{\circ} \mathrm{C}$ using an IMM micromixer [42] at each flow rate of $0.3 \mathrm{~mL} / \mathrm{min}$. After the reaction mixture was allowed to flow for additional 157 seconds through a reactor tube $(\varnothing=1.0$ $\mathrm{mm}, l=1.0 \mathrm{~m})$ at $90{ }^{\circ} \mathrm{C}$, the mixture was quenched by a saturated $\mathrm{NaHCO}_{3}$ solution at room temperature.
When $0.2 \mathrm{M}$ solution of $p$-TsOH was used, only a trace amount of 20 was obtained and the starting material 19 was largely recovered. However, we again found that the yield of the dehydrated compound depends on the concentration of the acid; 20 was finally obtained in $80 \%$ yield (total yield from farnesol 17) at an acid concentration of $1.0 \mathrm{M}$. The common features observed for the microfluidic $\alpha$-sialylation and the reductive opening of the benzylidene acetals, and opposed to the conventional batch reactions, can also be applied to the current dehydration; namely, the success of "very fast" acid-mediated reactions under the microfluidic conditions owes to the rapid micromixing with the concentrated acid. It is noted that under the established microfluidic conditions, the formation of other by-products could not be detected by TLC analysis.

Having established the optimal conditions for dehydration, the kilogram synthesis of pristane was examined (Scheme 1 and Figure 3) [29]. The crude alcohol 19, derived from $8 \mathrm{~kg}$ of farnesol 17 without any purification process, was subjected to the key microfluidic dehydration under the conditions established in Figure 3. For such a large-scale microfluidic reaction, we again introduced Comet X-01 [48], which we know from the previous examples, exhibited similar mixing efficiency to the IMM micromixer and avoids the blocking problem by using the relatively large tube hole (ca. $500 \mu \mathrm{m}$ ). This is especially useful for a synthetic process in which an easily crystallized material, such as $\mathrm{TsOH}$, is used at high concentration. Therefore, this mixer, together with its availability at a low price, is well suited for establishing a micro chemical plant. As shown in Figure 3, we arranged 10 micromixers in a row and achieved the eight
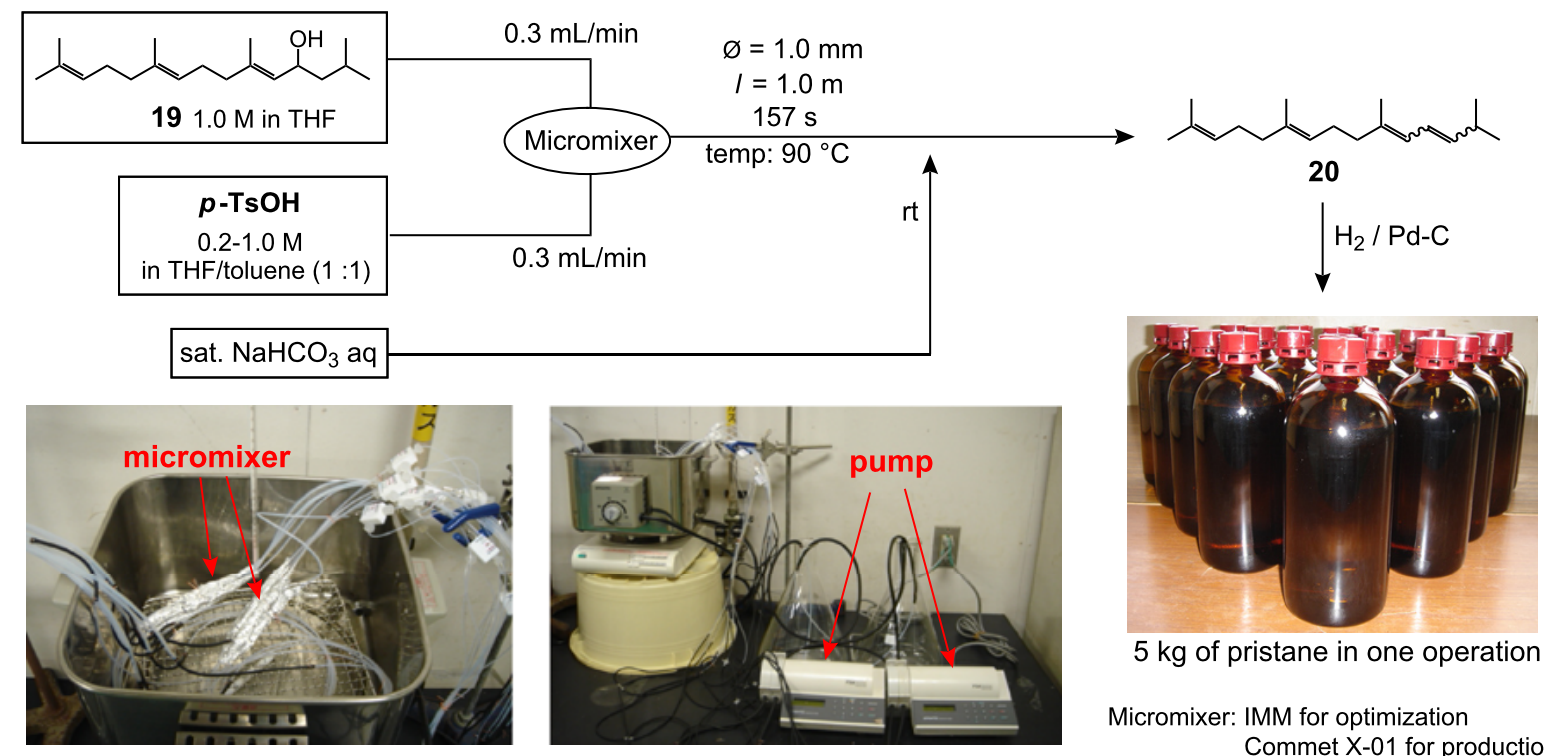

Micromixer: IMM for optimization Commet X-01 for production

Figure 3: Process synthesis of pristane via microfluidic dehydration as a key step. 


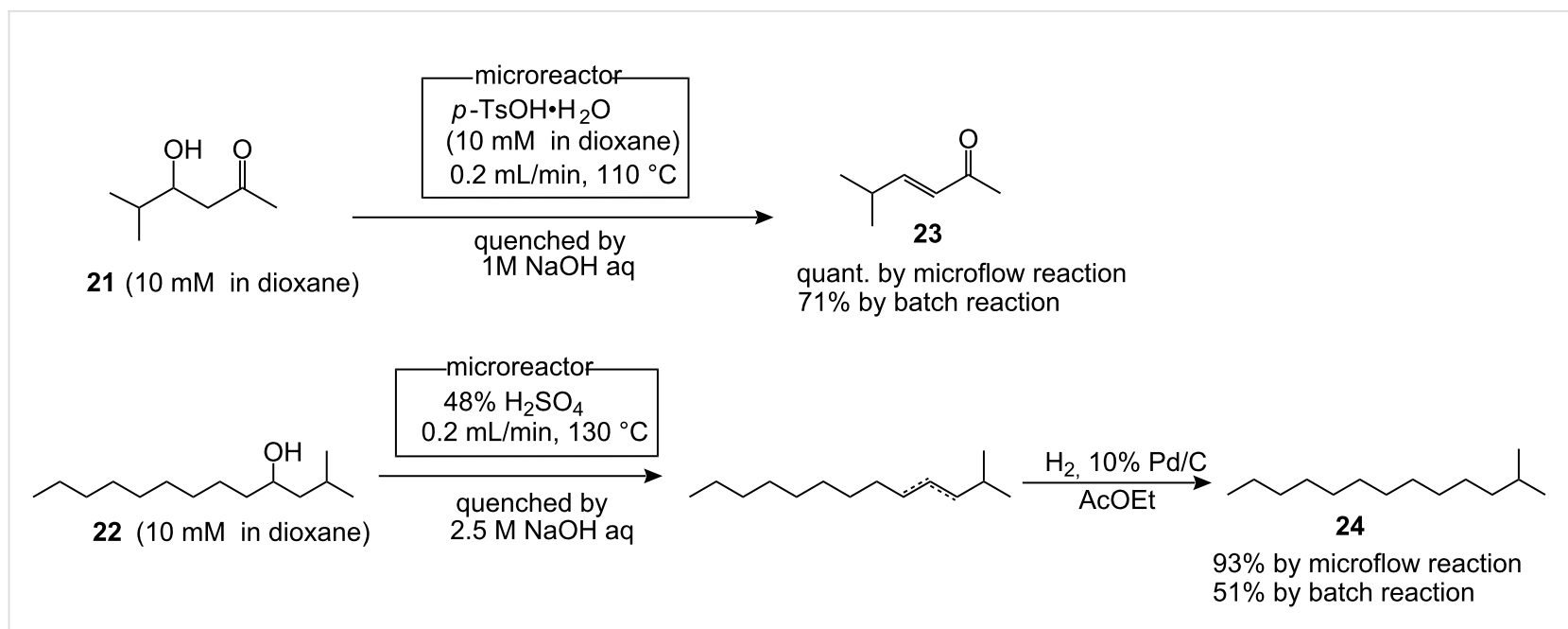

Scheme 2: Microfluidic dehydration.

kilogram-scale dehydration during 3-4 days. It is noted that the present micro chemical plant does not require any special apparatus or devices and such a simple system in Figure 3 continuously performed efficient dehydration. The resulting solution eluted from the micromixing system was quenched with a saturated $\mathrm{NaHCO}_{3}$ solution, extracted with ethyl acetate, concentrated, and the mixtures were shortly passed through a silica gel pad in order to remove the hydrophilic by-products, affording the pure diene $\mathbf{2 0}$.

Finally, the hydrogenation provided pristane in $50-55 \%$ overall yields (ca. $5 \mathrm{~kg}$ ) with $>99 \%$ purity based on gas chromatography analysis. Since the present pristane synthesis involves only one simple purification step by filtration with a silica gel pad, we believe that our protocol is superior to the hitherto known synthesis, which involves purification by tedious multiple distillation at the final stage. Indeed, the synthetic pristane formed by this route is confirmed to induce antibody production in mouse ascites twice as efficiently as natural pristane or the other synthetic products, due to non-negligible contamination of the other hydrophobic compounds [52-56].

In order to evaluate the efficiency of dehydration under the microfluidic conditions, the reactivity of $\beta$-hydroxyketone $\mathbf{2 1}$ and alkanol 22 were also tested (Scheme 2) [29]. Gratifyingly, both substrates provided the corresponding dehydrated products $\mathbf{2 3}$ and $\mathbf{2 4}$ in almost quantitative yields under the conditions established in Figure 3. For both cases, the conventional batch reaction gave lower yields of the products due to recovery of the starting materials and formation of other by-products. Therefore, an efficient and general protocol for dehydration was realized by using the micromixing system.

\section{Conclusions}

In conclusion, we have achieved efficient glycosylation, reductive opening of the benzylidene acetal groups, and dehydration under microfluidic conditions. During our research in applying the microfluidic systems to these acid-mediated reactions, a distinctly different reactivity from that in the conventional batch stirring was found: vigorous micromixing of the reactants with the concentrated acids is critical especially for the "fast" reactions to be successful. Such a common feature might be due to the integration of all favorable aspects of microfluidic conditions, namely, efficient mixing, precise temperature control, and the easy handling of the reactive intermediate by controlling the residence time. As can be seen from the three examples cited in this review, rapid determination of the reaction conditions is another aspect of using the microfluidic conditions in a combinatorial fashion. The efficiency of the acid-mediated microfluidic reactions cited in this review, together with the other successful flow reactions reported by us and the other researchers, indicate the need to reinvestigate the traditional or imaginary reactions which have so far been performed and evaluated only in batch apparatus, and therefore have not been widely utilized for organic synthesis. In other words, such reactions could be refocused as "new generation reactions". The authors strongly believe that the microfluidic reactions could be recognized as a new strategy for the synthesis of natural products of the prominent biological activity in a "practical" and a "industrial" manner.

\section{Acknowledgments}

We acknowledge Mr. Koichi Koyama and Mr. Keiichi Watanabe, Kishida Chemical Co., Ltd, for helpful discussion and arrangements for promoting the synthetic pristane in the market. The present work was conducted with the aid of the 
Micro-Chemical Plant Technology Union (MCPT) for the Project of Micro-Chemical Technology for Production, Analysis, and Measurement Systems financially supported by New Energy and Industrial Technology Development Organization (NEDO). This work was also partially supported by Grantsin-Aid for Scientific Research No. 19681024 and 19651095 from the Japan Society for the Promotion of Science, Collaborative Development of Innovative Seeds from Japan Science and Technology Agency (JST), NEDO (project ID: 07A01014a), Research Grants from Yamada Science Foundation as well as Molecular Imaging Research Program, Grants-in-Aid for Scientific Research from the Ministry of Education, Culture, Sports, Science and Technology (MEXT) of Japan.

\section{References}

1. Ehrfeld, W., Ed. Microreaction Technology; Springer: Berlin, 1998.

2. Manz, A.; Becker, H. Microsystem Technology in Chemistry and Life Sciences; Springer: Berlin, 1998.

3. Ehrfeld, W.; Hessel, V.; Löwe, H. Microreactors; Wiley-VCH: Weinheim, 2000. doi:10.1002/3527601953

4. Jähnisch, K.; Hessel, V.; Löwe, H.; Baerns, M. Angew. Chem., Int. Ed. 2004, 43, 406. doi:10.1002/anie.200300577

5. Hessel, V.; Hardt, S.; Lowe, H. Chemical Micro Process Engineering; Wiley-VCH: Weinheim, 2004. doi:10.1002/3527603042

6. Yoshida, J.-I.; Suga, S.; Nagaki, A. J. Synth. Org. Chem. Japan 2005, 63, 511.

7. Watts, P.; Haswell, S. J. Chem. Soc. Rev. 2005, 34, 235. doi:10.1039/b313866f

8. Geyer, K.; Codee, J. D. C.; Seeberger, P. H. Chem.-Eur. J. 2006, 12, 8434. doi:10.1002/chem.200600596

9. deMello, A. J. Nature 2006, 442, 394. doi:10.1038/nature05062

10. Kobayashi, J.; Mori, Y.; Kobayashi, S. Chem.-Asian J. 2006, 1, 22. doi:10.1002/asia.200600058

11. Mason, B. P.; Price, K. E.; Steinbacher, J. L.; Bogdan, A. R.; McQuade, D. T. Chem. Rev. 2007, 107, 2300. doi:10.1021/cr050944c

12. Ahmed-Omer, B.; Brandtand, J. C.; Wirth, T. Org. Biomol. Chem. 2007, 5, 733. doi:10.1039/b615072a

13. Fukuyama, T.; Rahman, M. T.; Sato, M.; Ryu, I. Synlett 2008, 151. doi:10.1055/s-2007-1000884

14. Yoshida, J.-I.; Nagaki, A.; Yamada, T. Chem.-Eur. J. 2008, 14, 7450. doi:10.1002/chem.200800582

15. Pennemann, H.; Hessel, V.; Löwe, H. Chem. Eng. Sci. 2004, 59, 4789. doi:10.1016/j.ces.2004.07.049

16. Jahnisch, K.; Hessel, V.; Löwe, H.; Baerns, M. Angew. Chem., Int. Ed. 2004, 43, 406. doi:10.1002/anie.200300577

17. Nagaki, A.; Togai, M.; Suga, S.; Aoki, N.; Mae, K.; Yoshida, J.-I. J. Am. Chem. Soc. 2005, 127, 11666. doi:10.1021/ja0527424

18. Ratner, D. M.; Murphy, E. R.; Jhunjhunwala, M.; Snyder, D. A.; Jensen, K. F.; Seeberger, P. H. Chem. Commun. 2005, 578.

19. Flögel, O.; Codee, J. D. C.; Seebach, D.; Seeberger, P. H. Angew. Chem., Int. Ed. 2006, 45, 7000. doi:10.1002/anie.200602167

20. Geyer, K.; Seeberger, P. H. Helv. Chim. Acta 2007, 90, 395. doi:10.1002/hlca.200790046

21. Watts, P.; Wiles, C. Chem. Commun. 2007, 443. doi:10.1039/b609428g

22. Carrel, F. R.; Geyer, K.; Codee, J. D. C.; Seeberger, P. H. Org. Lett. 2007, 9, 2285. doi:10.1021/ol0705503
23. Usutani, H.; Tomida, Y.; Nagaki, A.; Okamoto, H.; Nokami, T.; Yoshida, J. J. Am. Chem. Soc. 2007, 129, 3046. doi:10.1021/ja068330s

24. Tanaka, K.; Motomatsu, S.; Koyama, K.; Fukase, K. Tetrahedron Lett. 2008, 49, 2010. doi:10.1016/j.tetlet.2008.01.057

25. Nagaki, A.; Tomida, Y.; Yoshida, J. Macromolecules 2008, 41, 6322. doi:10.1021/ma800769n

26. Nagaki, A.; Takizawa, E.; Yoshida, J. J. Am. Chem. Soc. 2009, 131, 1654. doi:10.1021/ja809325a

27. Fukase, K.; Takashina, M.; Hori, Y.; Tanaka, D.; Tanaka, K.; Kusumoto, S. Synlett 2005, 2342. doi:10.1055/s-2005-872269

28. Tanaka, S.; Goi, T.; Tanaka, K.; Fukase, K. J. Carbohydr. Chem. 2007, 26, 369. doi:10.1080/07328300701634796

29. Tanaka, K.; Motomatsu, S.; Koyama, K.; Tanaka, S.; Fukase, K. Org. Lett. 2007, 9, 299. doi:10.1021/ol062777o

30. Tanaka, K.; Fukase, K. Synlett 2007, 164. doi:10.1055/s-2006-958410

31. Tanaka, K.; Mori, Y.; Fukase, K. J. Carbohydr. Chem. 2009, 28, 1. doi:10.1080/07328300802571129

32. Tanaka, K.; Fujii, Y.; Tokimoto, H.; Mori, Y.; Tanaka, S.; Bao, G.-m.; Siwu, E. R. O.; Nakayabu, A.; Fukase, K. Chem.-Asian J. 2009, 4, 574. doi:10.1002/asia.200800411

33. Tanaka, K.; Miyagawa, T.; Fukase, K. Synlett 2009, 1571. doi:10.1055/s-0029-1217343

34. Kamerling, J. P.; Boons, G.-J.; Lee, Y. C.; Suzuki, A.; Taniguchi, N.; Voragen, A. G. J., Eds. Analysis of Glycans, Polysaccharide Functional Properties \& Biochemistry of Glycoconjugate Glycans, Carbohydrate-mediated Interactions: Comprehensive Glycoscience, From Chemistry to Systems Biology; Elsevier: UK, 2007; Vol. II \& III.

35. Tanaka, K.; Masuyama, T.; Hasegawa, K.; Tahara, T.; Mizuma, H.; Wada, Y.; Watanabe, Y.; Fukase, K. Angew. Chem., Int. Ed. 2008, 47, 102. doi:10.1002/anie.200702989

36. Tanaka, K.; Masuyama, T.; Minami, K.; Fujii, Y.; Hasegawa, K.; Tahara, T.; Mizuma, H.; Wada, Y.; Watanabe, Y.; Fukase, K. Pept. Sci. 2007, 91. doi:10.2174/157019308785161684

37. Tanaka, K.; Fukase, K. Org. Biomol. Chem. 2008, 6, 815. doi:10.1039/b718157b

38. Tanaka, K.; Fukase, K. Mini-Rev. Org. Chem. 2008, 5, 153. doi:10.2174/157019308785161684

39. Kamerling, J. P.; Boons, G.-J.; Lee, Y. C.; Suzuki, A.; Taniguchi, N.; Voragen, A. G. J., Eds. Introduction to Glycoscience Synthesis of Carbohydrates: Comprehensive Glycoscience, From Chemistry to Systems Biology; Elsevier: UK, 2007; Vol. I.

40. Fraser-Reid, B. O.; Tatsuta, K.; Thiem, J., Eds. Glycoscience: Chemistry and Chemical Biology I-III; Springer: New York, 2001; Vol. I.

41. Tanaka, K.; Goi, T.; Fukase, K. Synlett 2005, 2958. doi:10.1055/s-2005-921889

42. IMM micromixer:. http://www.imm-main2.de/.

43. Crich, D.; Sun, S. J. Org. Chem. 1997, 62, 1198. doi:10.1021/jo962345z

44. Ito, Y.; Ohnishi, Y.; Ogawa, T.; Nakahara, Y. Synlett 1998, 1102. doi:10.1055/s-1998-1894

45. Abdel-Rahman, A. A.-H.; Jonke, S.; Ashry, E. S. H. E.; Schmidt, R. R. Angew. Chem., Int. Ed. 2002, 41, 2972. doi:10.1002/1521-3773(20020816)41:16<2972::AID-ANIE2972>3.0.CO ;2-4

46. Tanaka, S.; Takashina, M.; Tokimoto, H.; Fujimoto, Y.; Tanaka, K.; Fukase, K. Synlett 2005, 2325. doi:10.1055/s-2005-872678

47. Tanaka, K.; Fukase, K. Electronic Encyclopedia of Reagents for Organic Synthesis 2007. 
48. Comet X-01 micromixer:

http://homepage3.nifty.com/techno-applications/ or E-mail: yukio-matsubara@nifty.com

49. Greene, T. W.; Wuts, P. G. M. Protective Groups in Organic Synthesis; John Wiley and Sons Inc.: New York, 1991.

50. DeNinno, M. P.; Etienne, J. B.; Duplantier, K. C. Tetrahedron Lett. 1995, 36, 669. doi:10.1016/0040-4039(94)02348-F

51. Oikawa, M.; Liu, W.-C.; Nakai, Y.; Koshida, S.; Fukase, K.; Kusumoto, S. Synlett 1996, 1179. doi:10.1055/s-1996-5724

52. Bigelow, H. B.; Schroeder, W. C. Mem. Sears Found. Mar. Res. 1948, 189.

53. Matthews, L. H. Philos. Trans. R. Soc. Lond. B Biol. Sci. 1950, 234, 247. doi:10.1098/rstb. 1950.0003

54. Parker, H. W.; Stott, F. C. Zool. Meded. 1965, 40, 305

55. Compagno, L. J. V. FAO Fisheries Synopsis 1984, 4, 233.

56. Clark, E. National Geographic 1992, 182, 120.

57. Satoh, M.; Richards, H. B.; Shaheen, V. M.; Yoshida, H.; Naim, M. J. O.; Wooley, P. H.; Reeves, W. H. Clin. Exp. Immunol. 2000, 121, 399. doi:10.1046/j.1365-2249.2000.01276.x

58. Holmdahl, R.; Lorentzen, J. C.; Lu, S.; Olofsson, P.; Wester, L.; Holmberg, J.; Pettersson, U. Immunol. Rev. 2001, 184, 184. doi:10.1034/j.1600-065x.2001.1840117.x

59. Gado, K.; Silva, S.; Paloczi, K.; Domjan, G.; Falus, A. Haematologica 2001, 86, 227.

\section{License and Terms}

This is an Open Access article under the terms of the Creative Commons Attribution License

(http://creativecommons.org/licenses/by/2.0), which permits unrestricted use, distribution, and reproduction in any medium, provided the original work is properly cited.

The license is subject to the Beilstein Journal of Organic Chemistry terms and conditions:

(http://www.beilstein-journals.org/bjoc)

The definitive version of this article is the electronic one which can be found at: doi:10.3762/bjoc. 5.40 